\title{
Are Females at Greater Risk for Revision Surgery After Hip Resurfacing Arthroplasty With the Articular Surface Replacement Prosthesis?
}

\author{
Gabrielle S. Donahue BA, Viktor Lindgren MD, PhD, Vincent P. Galea BA, \\ Rami Madanat MD, PhD, Orhun Muratoglu PhD, Henrik Malchau MD, PhD
}

Received: 9 February 2016/Accepted: 20 April 2016/Published online: 27 April 2016

(C) The Association of Bone and Joint Surgeons (B) 2016

\begin{abstract}
Background Female patients undergoing hip resurfacing arthroplasties may be at greater risk of revision surgery than males, but it is unclear whether this is related to sex or other factors. We focused our analysis on data from a prospective multicenter cohort study monitoring the $\mathrm{ASR}^{\mathrm{TM}}$ hip resurfacing arthroplasty prosthesis on the potential association of sex on patient-reported outcome measures (PROMs), metal ion levels, revision surgery, and presence of adverse local tissue reaction. As thousands of patients with the $\mathrm{ASR}^{\mathrm{TM}}$ prosthesis are still undergoing followup it is critical to optimize the protocol for monitoring these patients.
\end{abstract}

One of the authors (HM) has received research support funding from Biomet (Warsaw, IN, USA), Smith \& Nephew (London, UK), Zimmer Inc (Warsaw, IN, USA), and Mako Surgical Corp (Ft Lauderdale, FL, USA). One of the authors (OM) has received research support funding from Mako Surgical Corp. The institution of one or more authors (RM, VG, GSD, CRB, OM, HM) has received, during the study period, funding from DePuy Synthes (Warsaw, IN, USA).

One of the authors (OM), or a member of his immediate family, has or may receive payments or benefits, during the study period, an amount of USD 10,000 to USD 100,000, from Zimmer Inc, Biomet, Corin (Cirencester, UK), Iconacy (Warsaw, IN, USA), Renovis (Redlands, CA, USA), Conformis (Burlington, MA, USA), Aston Medical (Saint-Étienne, France), Meril Healthcare (Vapi, Gujarat, India), Arthex (Naples, FL, USA), Mako Surgical Corp, Cambridge Polymer Group (Boston, MA, USA), and Orthopedic Technology Group (Boston, MA, USA).

One of the authors (HM), or a member of his immediate family, has or may receive payments or benefits, during the study period, an amount of USD 10,000 to USD 100,000, from Zimmer Inc, Biomet, Corin, and RSA Biomedical (Umeå, Sweden).

All ICMJE Conflict of Interest Forms for authors and Clinical Orthopaedics and Related Research ${ }^{\circledR}$ editors and board members are on file with the publication and can be viewed on request.
Questions/purposes We wished (1) to assess the associations between sex and implant survival, and adverse local tissue reaction; and (2) to report the differences between sexes in metal ion levels and patient-reported outcome measures.

Methods One thousand two hundred fifty-two patients (1390 hips) who underwent hip resurfacing arthroplasty with implantation of the $\mathrm{ASR}^{\mathrm{TM}}$ prosthesis from April 2003 to July 2010 were eligible for enrollment in a multicenter followup study of the ASR ${ }^{\mathrm{TM}}$ Hip Resurfacing System after the voluntary recall of this device was initiated by DePuy in 2010. Nine hundred seventy patients (1098 hips) were enrolled at a mean of 7 years after surgery, with a mean followup of 2 years (range, 1-3.5 years).

Clinical Orthopaedics and Related Research ${ }^{\circledR}$ neither advocates nor endorses the use of any treatment, drug, or device. Readers are encouraged to always seek additional information, including FDAapproval status, of any drug or device prior to clinical use.

Each author certifies that his or her institution approved the human protocol for this investigation, that all investigations were conducted in conformity with ethical principles of research, and that informed consent for participation in the study was obtained.

This work was performed at Massachusetts General Hospital, Boston, MA, USA.

G. S. Donahue, V. Lindgren, V. P. Galea, R. Madanat Harris Orthopaedic Laboratory, Massachusetts General Hospital, Boston, MA, USA

\section{Lindgren}

Department of Molecular Medicine and Surgery, Section of Orthopaedics, Karolinska Institute, Stockholm, Sweden

O. Muratoglu, H. Malchau ( $\square)$

Massachusetts General Hospital, 55 Fruit Street, GRJ 1231,

Boston, MA 02114, USA

e-mail: hmalchau@mgh.harvard.edu 
Nine hundred fifty-eight patients (1084 hips) met the inclusion criteria: ability to provide informed consent, complete PROMs, and continued routine followup. A subset of patients (150 patients, 171 hips), who all were from one center, with annual metal artifact reduction sequence MRI were analyzed. Ninety-three percent of patients from this center had routine MRI performed. The EuroQoL (EQ-5D), Harris hip score (HHS), University of California Los Angeles (UCLA) activity score, VAS pain, radiographs, patient and surgery details, and blood cobalt and chromium levels were obtained. Cox regression analysis was conducted to identify factors associated with implant survival, using any revision as the end point, and presence of adverse local tissue reaction.

Results In patients who had unilateral surgery, the only variable found to be associated with revision surgery was HHS (hazard ratio [HR], 0.96; 95\% CI, 0.94-0.97; p < 0.001 ). In patients who had bilateral surgery, only HHS (HR, 0.93; 95\% CI, 0.90-0.97; $\mathrm{p}<0.001$ ) and cobalt level (HR, $1.02 ; 95 \% \mathrm{CI}, 1.01-1.03 ; \mathrm{p}<0.001)$ were associated with risk for revision. In patients with metal artifact reduction sequence MRI, the only variable found to be associated with presence of adverse local tissue reaction was cobalt level (HR, 1.06; 95\% CI, 1.02-1.10; $\mathrm{p}=0.001$ ). Cobalt and chromium concentrations were greater in female patients than in male patients (cobalt, median 1.89 versus median 1.12 parts per billion [ppb], $\mathrm{p}<0.001$; chromium, median 2.03 versus median $1.17 \mathrm{ppb}, \mathrm{p}<0.001)$. Slight differences were observed between males and females in HHS (males median 96 versus females median 94, $\mathrm{p}<0.001$ ) and UCLA scores (median 8 versus median $6, \mathrm{p}<0.001$ ); however, there was no difference between sexes for VAS pain (median 0.5 versus median $0.5, \mathrm{p}=0.405$ ). Differences were identified between males and females in the distribution of EQ-5D scores, yet the medians were the same (median 1.0 versus median 1.0, $\mathrm{p}<0.001$ ).

Conclusions Male and female patients who had hip resurfacing arthroplasty with implantation of the $\mathrm{ASR}^{\mathrm{TM}}$ prosthesis should be followed with equal vigilance as both are at similar risk of revision surgery and adverse local tissue reaction. Metal ion levels and HHS should be obtained at followup to monitor for risk of revision and as a screening tool for MRI. Further research is necessary to evaluate if these relationships persist in patients with other metal-on-metal prostheses.

Level of Evidence Level II, therapeutic study.

\section{Introduction}

Ever since THA revolutionized the treatment of end-stage osteoarthritis, there have been many attempts to find the best-performing design and material to improve the longevity of the prosthesis [19]. Arthroplasties using metalon-metal (MoM) hip prostheses gained popularity during the last decade because this bearing surface promised the potential of low volumetric wear, which theoretically would reduce periprosthetic osteolysis [13]. This bearing surface also facilitated the use of larger head sizes, which reduced the risk of dislocation and enabled reintroduction of the hip resurfacing arthroplasty, which preserves proximal femoral bone stock $[12,26,30]$. To date, MoM bearings have been implanted in more than one million patients worldwide [4]. At the height of its use, hip resurfacing arthroplasties using MoM prostheses accounted for $29 \%$ to $46 \%$ of all primary THAs in patients younger than 55 years [21].

Despite these theoretical advantages of MoM implants, there have been reports of unacceptably high complication and revision rates resulting from adverse local tissue reaction and osteolysis [16]. Certain MoM implant designs have fared worse than others. The Articular Surface Replacement (ASR ${ }^{\mathrm{TM}}$ ) Hip Resurfacing System (DePuy Orthopaedics, Warsaw, IN, USA) was recalled in 2010 owing to a higher than expected revision rate at 5 years, after an estimated 93,000 components had been implanted in patients worldwide [6, 13, 35]. As thousands of MoM devices remain in circulation, establishing an appropriate protocol for monitoring these patients with these prostheses remains a critical issue.

It has been reported that $29 \%$ to $34 \%$ of hip resurfacing arthroplasties have been performed in females [6, 29, 31]. Some studies have indicated that females receiving hip resurfacing arthroplasties with MoM prostheses are at an especially high risk of revision surgery and report higher levels of pain compared with males $[3,14]$. A systematic review from 2015 exploring the effect of sex on complications after hip resurfacing arthroplasties found that female patients were at greater risk of adverse local tissue reaction, dislocation, aseptic loosening, and revision surgery [11]. However, female sex as a causative factor has been questioned, because implant size and positioning, anatomic differences, and the primary diagnosis might serve as confounders [1, 27]. Another conclusion of the systematic review was that arthroplasty research data often lack an adequate description of the sex distribution and its association with outcomes.

Therefore, we conducted an analysis of data from a prospective multicenter cohort study monitoring the hip resurfacing arthroplasty using the $\mathrm{ASR}^{\mathrm{TM}}$ prosthesis to ask the following questions: (1) What is the association between sex and implant survival, and the presence of adverse local tissue reaction in arthroplasties with MoM hip prostheses; and (2) are there differences between sexes in metal ion levels and patient-reported outcome measures 
(PROMs) in patients with arthroplasties with MoM hip resurfacing systems?

\section{Patients and Methods}

We performed a prospective, multicenter study of the $\mathrm{ASR}^{\mathrm{TM}}$ Hip Resurfacing System. Patients were enrolled after obtaining institutional review board approval and subsequently followed annually to and including their revision surgery, if applicable. The study was initiated after recall of the $\mathrm{ASR}^{\mathrm{TM}}$ Hip Resurfacing System; however data were collected prospectively with the aim of assessing potential predictors for various outcomes including adverse local tissue reactions, revision surgery, and patient-reported outcomes.

Data were collected from September 2012 to March 2016 at Massachusetts General Hospital (Boston, MA, USA), from the 16 participating sites located in six countries (United States, United Kingdom, Denmark, Italy, South Africa, and Australia) through a secure, web-based data entry system. Data collected included head size, blood metal ion levels, PROMs, patient and surgery details, presence of adverse local tissue reaction (if MRI was available), the presence or absence of revision surgery and revision indication, and AP pelvis radiographs for measurement of cup position. Blood metal ion levels, PROMs, and radiographs were collected annually.
Participants/Study Subjects

One thousand two hundred fifty-two patients (1390 hips) who underwent hip resurfacing arthroplasties with implantation of the ASR ${ }^{\mathrm{TM}}$ Hip Resurfacing System from April 2003 to July 2010 were eligible for enrollment in a multicenter followup study after voluntary recall of the device was initiated by DePuy in 2010. In total 970 patients (1098 hips) were enrolled in the study (Fig. 1). These patients met the following inclusion criteria: any patient (1) with on-label use of the ASR ${ }^{\mathrm{TM}}$ Hip Resurfacing System currently implanted; (2) able to give informed consent as approved by the ethics committee; (3) able to return for annual followup for a period of 5 years; and (4) able to competently complete the required PROMs. For our analyses, we divided the hips into two cohorts. In Cohort A, we included only the patients with the $\mathrm{ASR}^{\mathrm{TM}}$ prosthesis who had complete enrollment data as dictated by the study protocol: (1) demographic information; (2) surgical demographic information; (3) blood metal ion levels (chromium and cobalt) within 6 months of consent; (4) PROMs within 6 months of consent; (5) a valid AP pelvis plain radiograph dating a maximum of 2 years before consent; and (6) notification of and reason for revision, if applicable. This yielded 958 patients (1084 hips) for Cohort A. The mean age of patients in Cohort A at the time of index surgery was 56 years (range, 16-80 years) and 260 were females $(27 \%)$. The mean time from index surgery to

1252 Patients With the ASR ${ }^{\mathrm{TM}}$ Prosthesis With Unrevised Hip Resurfacing Arthroplasties Undergoing Followup from 2012 to 2015 from 16 Different Sites in Five Countries ( $n=1390$ hips)

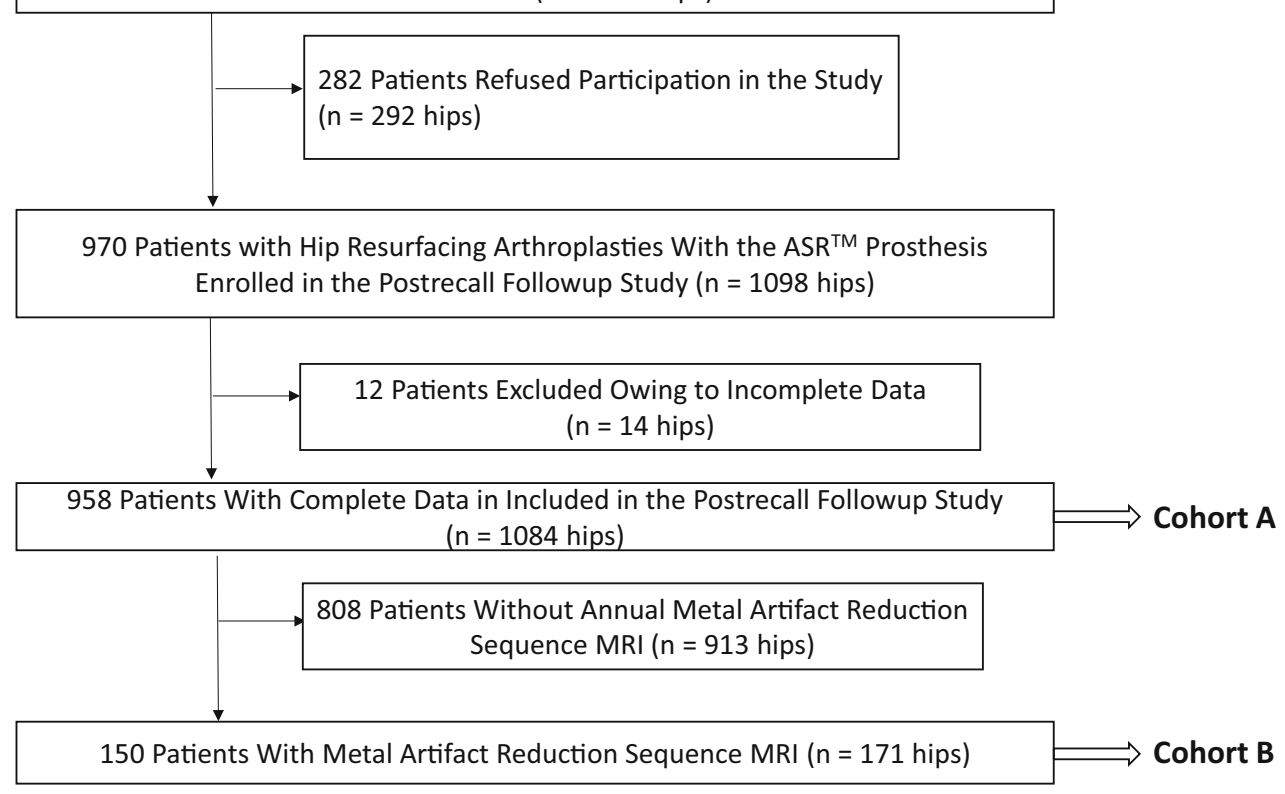

Fig. 1 The flowchart shows patient selection for Cohorts A and B in our study. 
Table 1. Demographics of the study population

\begin{tabular}{|c|c|c|c|c|c|c|}
\hline \multirow[b]{2}{*}{ Demographic } & \multicolumn{3}{|l|}{ Cohort A } & \multicolumn{3}{|l|}{ Cohort B } \\
\hline & Females & Males & $\mathrm{p}$ value & Females & Males & $\mathrm{p}$ value \\
\hline Number of patients & 260 & 698 & & 47 & 103 & \\
\hline Mean age at index surgery (years, range) & $55(27-72)$ & $56(16-80)$ & 0.006 & $54(30-67)$ & $55(26-69)$ & 0.464 \\
\hline Mean time from index surgery to followup (years, range) & $7.2(3.1-11.4)$ & $7.1(3.0-11.4)$ & 0.681 & $6.9(3.7-10.0)$ & $6.9(3.6-10.3)$ & 0.927 \\
\hline Median femoral head size (mm, range) & $46(39-61)$ & $51(45-61)$ & $<0.001$ & $49(41-61)$ & $55(46-61)$ & $<0.001$ \\
\hline Mean inclination angle (degrees, range) & $45(23-79)$ & $44(21-74)$ & 0.209 & $45(27-62)$ & $44(22-65)$ & 0.261 \\
\hline
\end{tabular}

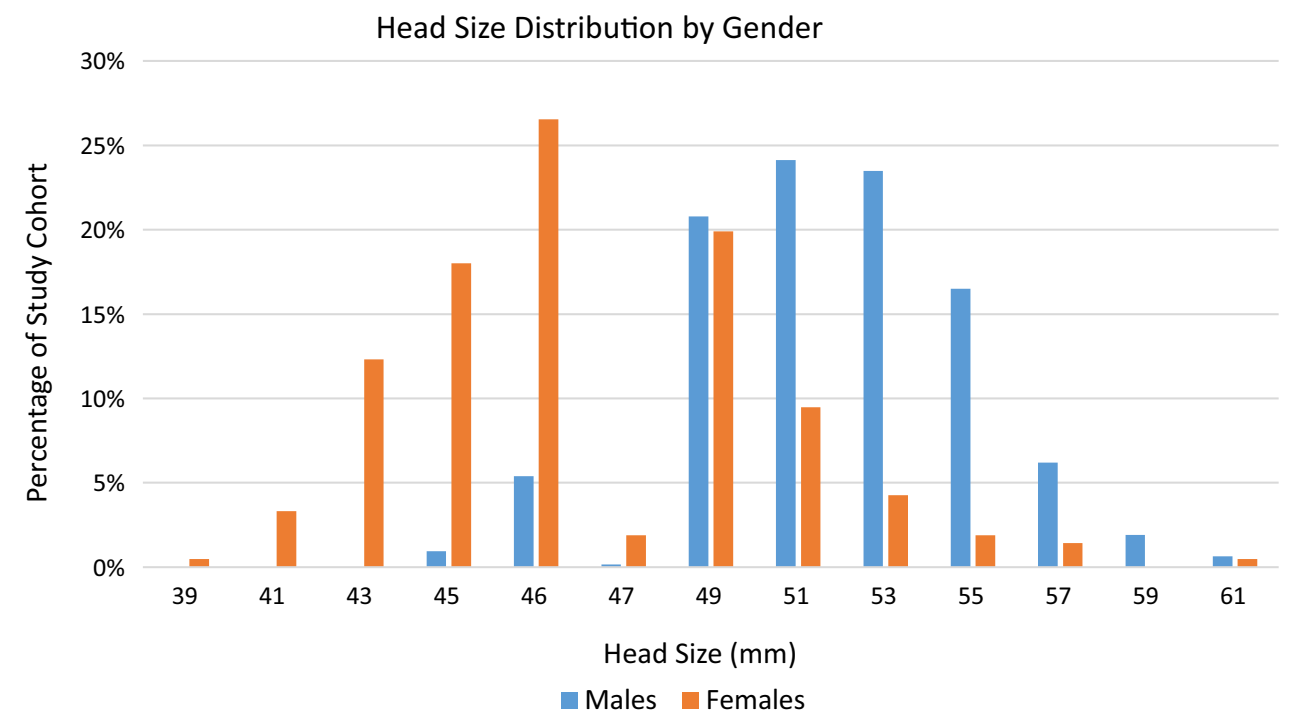

Fig. 2 Femoral head size distribution $(\mathrm{mm})$ was stratified by sex for patients in our study cohort.

followup was 7 years (range, 3-12 years). The mean time from index surgery to followup did not differ between males and females $(\mathrm{p}=0.681)$ (Table 1). The mean age at index surgery was 56 years (range, $16-80$ years) for males and 55 years (range, 27-72 years) for females $(\mathrm{p}=0.006)$. The median femoral head size was $46 \mathrm{~mm}$ (range, 39-61 $\mathrm{mm}$ ) for females and $51 \mathrm{~mm}$ for males (range, $45-61 \mathrm{~mm}$; $<0.001$ ) (Fig. 2). The median cup inclination angle was $44^{\circ}$ (range, $21^{\circ}-74^{\circ}$ ) for males and $45^{\circ}$ (range, $23^{\circ}-79^{\circ}$ ) for females $(\mathrm{p}=0.37)$ (Table 1).

Subcohort B was a subset of Cohort A; it included all patients from Cohort A who came from one center where metal artifact reduction sequence protocol MRI is performed annually [22]. One hundred fifty (171 hips) of the 161 patients (185 hips) undergoing annual followups at this center had MRI performed and comprised Cohort B. There were 103 males $(69 \%)$ and 47 females $(31 \%)$.

The PROMs were collected annually and included the EuroQoL five dimensions questionnaire (EQ-5D) [7] to indicate health-related quality of life, the Harris hip score (HHS) to indicate hip function, University of California Los Angeles (UCLA) activity score, and VAS for pain (0-
10). The level of anxiety or depression in patients receiving the $\mathrm{ASR}^{\mathrm{TM}}$ implant was assessed using the anxiety/depression domain of the EQ-5D questionnaire and the responses were dichotomized into no anxiety or any anxiety (moderate/severe). The cup inclination angle of the acetabular component was measured for each hip from collected radiographs using mdesk $^{\mathrm{TM}}$ software (RSA Biomedical, Umeå, Sweden) by three trained and validated observers.

MR images were assessed for the presence, location, and severity of adverse local tissue reactions. The severity was classified using the grading system of Anderson et al. [2, 22]. MRI assessment was performed by one of the authors (RM) with 2 years of experience and was validated by a musculoskeletal radiologist (HP) with more than 10 years of experience reading metal artifact reduction sequence protocol MR images. This assessment was blinded to all clinical and surgical patient data.

Whole blood cobalt and chromium metal ion concentrations were obtained annually at certified laboratories using a standardized protocol and reported in parts per billion (ppb). 
Statistical Analysis

A t-test for two independent samples was used to compare normally distributed variables and a Mann-Whitney U test was used for nonparametric continuous variables. The chisquare test was used in the assessment of categorical variables. Cumulative revision rates were calculated using the KaplanMeier survival method and compared using the log-rank test. We calculated relative risk of revision using Cox proportional hazards regression for patients with unilateral and bilateral arthroplasties separately. Fulfillment of the proportional hazards assumption in the Cox models was investigated by inspecting log-minus log curves and Schoenfeld residuals. Proportional hazards assumption was met in all analyses. The following independent variables were considered for potential confounding: female sex, blood chromium levels, blood cobalt levels, cup inclination angle, age at index surgery, head size, HHS, EQ-5D, UCLA score, VAS pain, and EQ-5D anxiety/depression. The same methods were used for Cohort $\mathrm{B}$ to assess the relationship between moderate or severe adverse local tissue reaction and the same set of independent risk factors from the analysis of Cohort A was used. Owing to the small number of patients with bilateral arthroplasties in Cohort B, only patients with unilateral arthroplasties were assessed in the Cox regression model exploring adverse local tissue reaction as an outcome. Adverse local tissue reactions were categorized as a dichotomous outcome variable with moderate-to-severe adverse local tissue reactions classified as complications. Interobserver reliability for the assessment of adverse local tissue reaction grade was performed using Cohen's kappa ( $\kappa)$. Interobserver reliability for assessment of adverse local tissue reaction grade $(\kappa=0.64)$ was substantial. A probability less than 0.05 was considered significant. Statistical analyses were performed using SPSS Version 17.0 (SPSS Inc, Chicago, IL, USA).

\section{Results}

Sex/Gender and Implant Survival and Adverse Local

Tissue Reaction

The cumulative revision rate at 11 years was higher for female patients (20/294 hips, $12 \%$; 95\% CI, 6\%-17\%) than for male patients $(20 / 790$ hips, $5 \%$; $95 \%$ CI, $2 \%-7 \%$; p = 0.002). However, after controlling for confounding variables, the only variable found to be associated with revision surgery in patients with unilateral surgery was the HHS (hazard ratio [HR], 0.96; 95\% CI, 0.94-0.97; p < 0.001). In patients who had bilateral surgery, the only variables found to be associated with revision surgery were HHS (HR, 0.93; 95\% CI, 0.90-0.97; p < 0.001) and cobalt level (HR, 1.02; 95\% CI, 1.01-1.03; p < 0.001) (Table 2). Increasing cobalt levels (HR, 1.06; CI, 1.02-1.10; p = 0.001 ) were associated with increased risk for adverse local tissue reaction.

Forty-one hips (4\%) were revised during the study period. Twenty-one of the 698 male patients underwent revision surgery (3\%), and 20 of the 260 female patients underwent revision surgery $(8 \%)$. The mean time from index to revision surgery was 8 years (range, 4-11 years) for males and 8 years (range, 5-10 years) for females ( $\mathrm{p}=$ 0.756). No revisions were performed for infection or dislocation. Multiple reasons for revision were reported for each hip, including bony tissue necrosis $(\mathrm{n}=14)$, MRIverified soft tissue change $(\mathrm{n}=19)$, patient demand $(\mathrm{n}=$ $16)$, aseptic loosening $(n=7)$, osteolysis $(n=21)$, physician recommendation $(\mathrm{n}=21)$, and pain $(\mathrm{n}=28)$. Patient demand and physician recommendation always were accompanied by another clinical indicator for revision.

Moderate-to-severe adverse local tissue reactions were identified in 29 of the 171 hips (17\%) with metal artifact reduction sequence protocol MRI, 14 of which were in female patients (30\% of females) and 15 in male patients ( $15 \%$ of males). Eighteen of the 171 hips in Cohort B were revised.

\section{Sex/Gender and Metal Ion Levels and PROMs}

Cobalt and chromium concentrations were greater in female patients than males (cobalt, median 1.89 ppb versus $1.12 \mathrm{ppb}, \mathrm{p}<0.001$; chromium, median $2.03 \mathrm{ppb}$ versus $1.17 \mathrm{ppb}, \mathrm{p}<0.001$ ) (Table 3 ). Male patients generally reported better PROMs. They had slightly higher HHS (median, 96 versus 94; p $<0.001$ ) and UCLA scores (median, 8 versus $6 ; \mathrm{p}<0.001$ ) than female patients;

Table 2. Results of multivariable Cox regression analysis

\begin{tabular}{llllll}
\hline Variable & $\begin{array}{l}\text { Cohort A } \\
\text { unilateral surgery }\end{array}$ & & $\begin{array}{l}\text { Cohort B } \\
\text { bilateral surgery }\end{array}$ \\
\cline { 2 - 3 } \cline { 5 - 6 } & Hazard ratio value (95\% CI) final model & p value & & Hazard ratio value (95\% CI) final model & $\mathrm{p}$ value \\
\hline $\begin{array}{l}\text { Harris hip score } \\
\text { Blood cobalt level }(\mathrm{ppb})\end{array}$ & $0.96(0.94-0.97)$ & $<0.001$ & & $0.93(0.90-0.97)$ & $<0.001$ \\
\hline
\end{tabular}

$\mathrm{ppb}=$ parts per billion 
Table 3. Median and range values of blood metal ion levels and PROMs

\begin{tabular}{|c|c|c|c|c|c|c|}
\hline \multirow[b]{2}{*}{ Variable } & \multicolumn{3}{|l|}{ Cohort A } & \multicolumn{3}{|l|}{ Cohort B } \\
\hline & Female patients & Male patients & $\mathrm{p}$ value & Female patients & Male patients & $\mathrm{p}$ value \\
\hline Number of patients & 260 & 698 & & 47 & 103 & \\
\hline Cobalt (ppb) & $1.83(0.0-258.0)$ & $1.12(0.0-199.1)$ & $<0.0001$ & $1.94(0.5-26.4)$ & $1.30(0.4-21.8)$ & 0.026 \\
\hline Chromium (ppb) & $2.03(0.0-69.2)$ & $1.15(0.0-115.8)$ & $<0.0001$ & $2.5(0.5-19.4)$ & $1.46(0.0-22.8)$ & 0.001 \\
\hline Harris hip score & $94(34-100)$ & $96(27-100)$ & $<0.0001$ & $87(34-100)$ & $92(41-100)$ & 0.013 \\
\hline EQ-5D & $1.00(0.06-1.00)$ & $1.00(0.00-1.00)$ & $<0.0001$ & $0.796(0.29-1.00)$ & $1.00(0.12-1.00)$ & 0.012 \\
\hline UCLA & $6(2-10)$ & $8(2-10)$ & $<0.0001$ & $6(4-10)$ & $7(3-10)$ & $<0.001$ \\
\hline VAS pain & $0.5(0.0-8.5)$ & $0.5(0.0-9.5)$ & 0.471 & $0.5(0.0-5.5)$ & $0.5(0.0-9.5)$ & 0.174 \\
\hline VAS satisfaction & $0.5(0-10)$ & $0.5(0-10)$ & 0.130 & $1.5(0-10)$ & $0.5(0-10)$ & 0.182 \\
\hline
\end{tabular}

$\mathrm{ppb}=$ parts per billion;

EQ-5D EuroQol five dimension;

UCLA = University of California Los Angeles

however, there was no difference in VAS pain (median, 0.5 versus $0.5 ; p=0.405$ ). Although males and females had the same median EQ-5D scores (1.0), the Mann-Whitney U test identified differences in the spread of the data between these two groups $(p<0.001)$ (Table 3). Similar findings were observed in PROMs and metal ion levels in Subcohort B (Table 3). Cobalt and chromium ion levels were found to be higher in females than males (cobalt, median $1.85 \mathrm{ppb}$ versus $1.30 \mathrm{ppb}, \mathrm{p}=0.03$; chromium, median 2.5 ppb versus $1.5 \mathrm{ppb}, \mathrm{p}=0.001)$. Male patients had higher HHS (median, 92 versus 87; $p<0.001$ ), UCLA (median, 7 versus 6 ; $p<0.001$ ), and EQ-5D scores (median, 1.0 versus $0.80 ; \mathrm{p}<0.001$ ) and lower pain scores (median, 0.5 versus $1.0 ; \mathrm{p}<0.001)$ than female patients (Table 3 ).

\section{Discussion}

Female sex has been identified as a risk factor for revision surgery in hip resurfacing arthroplasty and has been associated with more complications, yet studies have failed to account for confounding variables and have analyzed multiple implants in the same cohort [3, 5, 8, 14]. As the $\mathrm{ASR}^{\mathrm{TM}}$ implant has been known to have a higher incidence of revision and increased prevalence of adverse local tissue reaction compared with other MoM hip resurfacing arthroplasty devices, we thought it was important to assess this implant. It is imperative to fully understand what patient-related and implant-related risk factors exist for complicated outcomes such as revision surgery and adverse local tissue reaction to establish an appropriate protocol for the followup of the thousands of patients with this implant in situ.

After controlling for confounding variables, we found female sex had no association with either revision surgery or presence of adverse local tissue reaction in patients with unilateral or bilateral surgeries. Cobalt and chromium concentrations are greater in female patients. Although male patients reported slightly better PROMs, most of these differences do not meet the minimal clinically important differences that would identify a true clinical change perceived by the patient.

Our study has some limitations. First, revision surgery is a consequence of many variables and does not take into account patients who choose to live with a painful hip, patients with high metal ion levels who are asymptomatic and being monitored, patients with unidentified soft tissue reactions, and those awaiting revision surgery. Second, patient demand and physician recommendation were reported to be revision decision factors for several cases in this study. Although not the primary reasons for revision, this creates a possible source of selection bias as a recalled device affects patient demand for revision. Additionally, the survival analyses we conducted were performed on a selected cohort of patients with the $\mathrm{ASR}^{\mathrm{TM}}$ prosthesis who did not have revision surgery at the time the voluntary recall was issued by DePuy. However, we are capturing complication and revision data on the patient population that still is undergoing followup, which is important because we are trying to understand the mid- to late-term consequences of the $\mathrm{ASR}^{\mathrm{TM}}$ prosthesis. Furthermore, because our study includes only patients with the $\mathrm{ASR}^{\mathrm{TM}}$ prosthesis, we cannot extrapolate our results to patients with other MoM devices. We also were unable to assess the associations between other possible confounding variables and revision, such as BMI, as it was not collected for all patients in the study, and dysplasia, as none of the 27 dysplastic hips in our study were revised. However, other studies in similar patient populations have not identified a relationship between BMI and revision incidence $[3,14]$.

In our study, female sex was not found to be an independent predictor of revision surgery. This finding is 
inconsistent with a recent study conducted at one center following a cohort of patients with 1064 MoM hip resurfacing implants $\left(67 \% \mathrm{BHR}^{\mathrm{TM}}\right.$ [Smith \& Nephew, Memphis, TN, USA]; 30\% Durom ${ }^{\circledR}$ [Zimmer Inc, Warsaw, IN, USA], and $3 \% \mathrm{ASR}^{\mathrm{TM}}$ ), which identified female sex as an independent predictor of lower survival [3]. Our study, however, accounts for a more robust set of confounding variables including metal ion levels and multiple PROMs. We did find a higher cumulative revision rate in female compared with male patients $(12 \%, 95 \%$ CI, $6 \%$ $17 \%$, vs $5 \%, 95 \% \mathrm{CI}, 2 \%-7 \%$ ), which has been identified in a registry study. The $11^{\text {th }}$ annual report from the National Joint Registry for England, Wales and Northern Ireland [24] cited a 7-year revision rate in males of $6 \%$ to $7 \%$ and $11 \%$ to $15 \%$ in females.

Sex and/or gender has been identified as an independent risk factor for patients undergoing revision surgery $[3,8$, 11, 14]. In a study examining 1419 arthroplasties using MoM prostheses, performed at one center, following four different devices, only female sex and young age were independent predictors for the risk of revision [8]. This study did not include patients with the $\mathrm{ASR}^{\mathrm{TM}}$ Hip Resurfacing System and captured only revisions resulting from pseudotumors as an endpoint. Bornert et al. [3] assessed the revision rate and PROMS in 931 patients who underwent hip resurfacing arthroplasties at one center; only 30 of the arthroplasties used the $\mathrm{ASR}^{\mathrm{TM}}$ system. They found female sex, length of followup, and steep inclination angle $\left(\geq 55^{\circ}\right)$ were independent risk factors for revision surgery. The only predictor of medium to late-term revision surgery in our cohort of patients who had unilateral arthroplasty was HHS. In patients who had bilateral arthroplasties, only HHS and cobalt levels remained significant predictors of revision surgery. These findings are partly consistent with those of some studies which have found elevated blood cobalt concentrations to be a risk factor for joint failure [10, 17]. Our findings, however, deviate from those of the aforementioned studies identifying female sex as an independent predictor of revision surgery. This may be because our study is the first, to our knowledge, to investigate these relationships, while accounting for important confounding variables like metal ion levels, implant position, implant size, and PROMs in a large cohort of patients who had implantation of strictly the $\mathrm{ASR}^{\mathrm{TM}}$ Hip Resurfacing System.

Our findings are in partial agreement with those of Bornert et al. [3], because they also observed that implant size was not a predictor of revision surgery. However, we did not find cup inclination angle, tested either as a continuous variable or a categorical variable $\left(\geq 55^{\circ}\right)$, to be a predictor of revision surgery. This is noteworthy, because steep inclination angle was found to be a risk factor for high metal ion levels, wear, and revision surgery [5, 20].
De Haan et al. [5] identified small implant size $(<50 \mathrm{~mm})$ and steep cup inclination angle $\left(\geq 55^{\circ}\right)$ as risk factors for revision, although only eight of the 214 patients who underwent hip resurfacing arthroplasty had implantation of an $\mathrm{ASR}^{\mathrm{TM}}$ prosthesis.

In our Cox regression model exploring the outcome of adverse local tissue reaction in a subcohort of patients with annual MRI, we found only blood cobalt levels to be predictive of moderate to severe adverse local tissue reaction. Bornert et al. [3] found the only independent factor associated with adverse reaction to metal debris in patients undergoing hip resurfacing arthroplasty with a MoM prosthesis to be cup inclination angle of $55^{\circ}$ or greater. Our results, however, revealed no correlation between cup inclination angle and moderate to severe adverse local tissue reaction. Another study of a cohort of 142 patients with the $\mathrm{ASR}^{\mathrm{TM}}$ prosthesis found only small cup coverage to be a predictor of adverse reaction to metal debris [28]. Glyn-Jones et al. [8] found females to be at increased risk for pseudotumors; however, because of a small sample size, they were unable to assess the individual associations between the various risk factors and prevalence of pseudotumors.

We found female patients have higher cobalt and chromium ion levels among patients with the $\mathrm{ASR}^{\mathrm{TM}}$ prosthesis, which is consistent with other studies [5, 23, 34]. Several studies have found females have higher rates of cobalt and nickel allergy than males and largely attribute this disparity to increased exposure to nickel- and cobaltreleasing metals in inexpensive jewelry or to elevated estrogen levels during puberty $[9,15,33,36]$. Information regarding chromium is scarcer, yet cobalt and chromium are strong sensitizers and can cause allergy with increased exposure. Increased sensitization to metal allergy may contribute to the elevated metal ion levels observed in female patients with MoM implants. We also found male patients had slightly higher HHS, quality of life (EQ-5D), and UCLA activity scores. Differences in EQ-5D and HHS must be observed with caution as they did not reach minimal clinically important differences. The EQ-5D has been shown to have a mean minimal clinically important difference in patients having THA of 0.31 [25], while the HHS has minimal clinically important differences of 7 to 9 [32]. There is no established minimal clinically important difference for the UCLA activity score. Our findings are consistent with those from another study which found female sex to be associated with worse UCLA, EQ-5D, and HHS [3].

Our study provides one of the most comprehensive multicenter analyses of mid-term survival of the $\mathrm{ASR}^{\mathrm{TM}}$ Hip Resurfacing System. Furthermore, only one previous study focused specifically on the ASR ${ }^{\mathrm{TM}}$ prosthesis, which is known to have a lower survival rate than other MoM 
devices [29]. This is likely attributable to the specific design differences between the $\mathrm{ASR}^{\mathrm{TM}}$ and similar hip resurfacing devices. The $\mathrm{ASR}^{\mathrm{TM}}$ acetabular component is subhemispheric and offers reduced cup coverage compared with similar devices [18]. Our study corroborates this theory as our analyses failed to identify female sex as a predictor of revision surgery or adverse local tissue reaction. The only factors associated with revision were low HHS in patients with unilateral and bilateral arthroplasties using the $\mathrm{ASR}^{\mathrm{TM}}$ prosthesis, and high cobalt levels only observed in patients who had bilateral arthroplasties. Only elevated cobalt levels were associated with prevalence of adverse local tissue reaction. Because we are reporting on the mid- to late-term followup of these patients, it is possible that revisions that previously were attributed to head size and cup inclination angle mostly occurred during the early followup stage $[6,27]$. Therefore it might be worthwhile to shift our clinical focus away from these variables as our data indicate they do not remain independent risk factors during the latter phases of followup. Our large multicenter study provides additional evidence that registry data can provide some insight into revision risk by sex and other collected demographic information; however, without collecting other confounding variables, such as metal ion levels, analyses may fall short of predicting all independent risk factors for revision surgery. Future efforts must be directed at distinguishing the mechanisms of failure at different times after index surgery. When considering a recalled implant, surgeons need to understand whether the previously reported mechanisms of failure are still of clinical consequence, and, if not, whether more relevant, mid- to late-term mechanisms of failure can be identified and subsequently stratified in terms of risk.

Acknowledgments We thank Slav Lerner BA (Harris Orthopaedic Laboratory, Massachusetts General Hospital) for his efforts in coordinating this study and Hollis Potter MD (Department of Radiology and Imaging, Hospital for Special Surgery, New York, NY, USA) for her efforts in metal artifact reduction sequence protocol MRI analysis.

\section{References}

1. Amstutz H, Le Duff M. Letter to the editor: do complication rates differ by gender after metal-on-metal hip resurfacing arthroplasty? A systematic review. Clin Orthop Relat Res. 2015;473:3981-3982.

2. Anderson H, Toms AP, Cahir JG, Goodwin RW, Wimhurst J, Nolan JF. Grading the severity of soft tissue changes associated with metal-on-metal hip replacements: reliability of an MR grading system. Skeletal Radiol. 2011;40:303-307.

3. Bornert S, Lutzner J, Beyer F, Gunther KP, Hartmann A. Revision rate and patient-reported outcome after hip resurfacing arthroplasty: a concise follow-up of 1064 cases. J Arthroplasty. 2015;30:2190-2195.

4. Bozic KJ, Kurtz S, Lau E, Ong K, Chiu V, Vail TP, Rubash HE, Berry DJ. The epidemiology of bearing surface usage in total hip arthroplasty in the United States. J Bone Joint Surg Am. 2009;91:1614-1620.

5. De Haan R, Pattyn C, Gill HS, Murray DW, Campbell PA, De Smet K. Correlation between inclination of the acetabular component and metal ion levels in metal-on-metal hip resurfacing replacement. J Bone Joint Surg Br. 2008;90:1291-1297.

6. de Steiger RN, Hang JR, Miller LN, Graves SE, Davidson DC. Five-year results of the ASR XL Acetabular System and the ASR Hip Resurfacing System: an analysis from the Australian Orthopaedic Association National Joint Replacement Registry. $J$ Bone Joint Surg Am. 2011;93:2287-2293.

7. EuroQolGroup. EuroQol: a new facility for the measurement of health-related quality of life. Health Policy. 1990;16:199-208.

8. Glyn-Jones S, Pandit H, Kwon YM, Doll H, Gill HS, Murray DW. Risk factors for inflammatory pseudotumour formation following hip resurfacing. J Bone Joint Surg Br. 2009;91:1566-1574.

9. Hamann CR, Hamann D, Hamann C, Thyssen JP, Liden C. The cost of nickel allergy: a global investigation of coin composition and nickel and cobalt release. Contact Dermatitis. 2013;68:15-22.

10. Hart AJ, Sabah SA, Sampson B, Skinner JA, Powell JJ, Palla L, Pajamaki KJ, Puolakka T, Reito A, Eskelinen A. Surveillance of patients with metal-on-metal hip resurfacing and total hip prostheses: a prospective cohort study to investigate the relationship between blood metal ion levels and implant failure. J Bone Joint Surg Am. 2014;96:1091-1099.

11. Haughom BD, Erickson BJ, Hellman MD, Jacobs JJ. Do complication rates differ by gender after metal-on-metal hip resurfacing arthroplasty? A systematic review. Clin Orthop Relat Res. 2015;473:2521-2529.

12. Hing C, Back D, Shimmin A. Hip resurfacing: indications, results, and conclusions. Instr Course Lect. 2007;56:171-178.

13. Huang DC, Tatman P, Mehle S, Gioe TJ. Cumulative revision rate is higher in metal-on-metal THA than metal-on-polyethylene THA: analysis of survival in a community registry. Clin Orthop Relat Res. 2013;471:1920-1925.

14. Jameson SS, Baker PN, Mason J, Porter ML, Deehan DJ, Reed MR. Independent predictors of revision following metal-on-metal hip resurfacing: a retrospective cohort study using National Joint Registry data. J Bone Joint Surg Br. 2012;94:746-754.

15. Krecisz B, Chomiczewska D, Palczynski C, Kiec-Swierczynska M. Contact allergy to metals in adolescents: nickel release from metal accessories 7 years after the implementation of the EU Nickel Directive in Poland. Contact Dermatitis. 2012;67:270-276.

16. Langton DJ, Jameson SS, Joyce TJ, Gandhi JN, Sidaginamale R, Mereddy P, Lord J, Nargol AV. Accelerating failure rate of the ASR total hip replacement. J Bone Joint Surg Br. 2011;93:10111016

17. Langton DJ, Sidaginamale RP, Joyce TJ, Natu S, Blain P, Jefferson RD, Rushton S, Nargol AV. The clinical implications of elevated blood metal ion concentrations in asymptomatic patients with MoM hip resurfacings: a cohort study. BMJ Open. 2013;3:pii: e001541. doi: 10.1136/bmjopen-2012-001541.

18. Langton DJ, Sprowson AP, Joyce TJ, Reed M, Carluke I, Partington P, Nargol AV. Blood metal ion concentrations after hip resurfacing arthroplasty: a comparative study of articular surface replacement and Birmingham Hip Resurfacing arthroplasties. $J$ Bone Joint Surg Br. 2009;91:1287-1295.

19. Learmonth ID, Young C, Rorabeck C. The operation of the century: total hip replacement. Lancet. 2007;370:1508-1519.

20. Leslie IJ, Williams S, Isaac G, Ingham E, Fisher J. High cup angle and microseparation increase the wear of hip surface replacements. Clin Orthop Relat Res. 2009;467:2259-2265.

21. Mabilleau G, Kwon YM, Pandit H, Murray DW, Sabokbar A. Metal-on-metal hip resurfacing arthroplasty: a review of periprosthetic biological reactions. Acta Orthop. 2008;79:734747. 
22. Madanat R, Hussey DK, Donahue GS, Potter HG, Wallace R, Bragdon CR, Muratoglu OK, Malchau $\mathrm{H}$. The symmetry of adverse local tissue reactions in patients with bilateral simultaneous and sequential ASR hip replacement. J Arthroplasty. 2015;30:1794-1798.

23. Moroni A, Savarino L, Hoque M, Cadossi M, Baldini N. Do ion levels in hip resurfacing differ from metal-on-metal THA at midterm? Clin Orthop Relat Res. 2011;469:180-187.

24. NJR National Joint Registry. National Joint Joint Registry for England, Wales and Northern Ireland, 11th Annual Report. Available at: http://www.njrcentre.org.uk/njrcentre/Portals/0/ Documents/England/Reports/11th_annual_report/NJR\%2011th\% 20Annual\%20Report\%202014.pdf. Accessed April 11, 2016.

25. Paulsen A, Roos EM, Pederson AB, Overgaard S. Minimal clinically important improvement (MCII) and patient-acceptable symptom state (PASS) in total hip arthroplasty (THA) patients 1 year postoperatively. Acta Orthop. 2014;85:39-48.

26. Pollard TC, Baker RP, Eastaugh-Waring SJ, Bannister GC. Treatment of the young active patient with osteoarthritis of the hip: a five- to seven-year comparison of hybrid total hip arthroplasty and metal-on-metal resurfacing. J Bone Joint Surg Br. 2006;88:592-600.

27. Prosser GH, Yates PJ, Wood DJ, Graves SE, de Steiger RN, Miller LN. Outcome of primary resurfacing hip replacement: evaluation of risk factors for early revision. Acta Orthop. 2010;81:66-71.

28. Reito A, Puolakka T, Elo P, Pajamaki J, Eskelinen A. High prevalence of adverse reactions to metal debris in small-headed ASR $^{\mathrm{TM}}$ hips. Clin Orthop Relat Res. 2013;471:2954-2961.
29. Seppanen M, Makela K, Virolainen P, Remes V, Pulkkinen P, Eskelinen A. Hip resurfacing arthroplasty: short-term survivorship of 4,401 hips from the Finnish Arthroplasty Register. Acta Orthop. 2012;83:207-213.

30. Singh G, Meyer H, Ruetschi M, Chamaon K, Feuerstein B, Lohmann $\mathrm{CH}$. Large-diameter metal-on-metal total hip arthroplasties: a page in orthopedic history? J Biomed Mater Res A. 2013;101:3320-3326.

31. Smith AJ, Dieppe P, Vernon K, Porter M, Blom AW; National Joint Registry of England and Wales. Failure rates of stemmed metal-on-metal hip replacements: analysis of data from the National Joint Registry of England and Wales. Lancet. 2012; 379:1199-1204.

32. Smith MV, Klein SE, Clohisy JC, Baca GR, Brophy RH, Wright RW. Lower extremity-specific measures of disability and outcomes in orthopaedic surgery. J Bone Joint Surg Am. 2012;94: 468-477.

33. Veien NK, Hattel T, Justesen O, Norholm A. Why do young girls become nickel sensitive? Contact Dermatitis. 1986;15: 306-307.

34. Vendittoli PA, Amzica T, Roy AG, Lusignan D, Girard J, Lavigne M. Metal ion release with large-diameter metal-on-metal hip arthroplasty. J Arthroplasty. 2011;26:282-288.

35. Whitwell GS, Shine A, Young SK. The articular surface replacement implant recall: a United Kingdom district hospital experience. Hip Int. 2012;22:362-370.

36. Wohrl S, Hemmer W, Focke M, Gotz M, Jarisch R. Patch testing in children, adults, and the elderly: influence of age and sex on sensitization patterns. Pediatr Dermatol. 2003;20:119-123. 